\title{
AVALIAÇÃO CINÉTICA DA PRODUÇÃo DE BIOSSURFACTANTES BACTERIANOS
}

\author{
Marta Heidtmann Pinto, Roberta Guimarães Martins e Jorge Alberto Vieira Costa* \\ Escola de Química e Alimentos, Universidade Federal do Rio Grande, CP 474, 96201-900 Rio Grande - RS, Brasil
}

Recebido em 10/11/08; aceito em 22/4/09; publicado na web em 31/8/09

\begin{abstract}
BACTERIA BIOSURFACTANTS PRODUCTION KINETIC EVALUATION. Biosurfactants present advantages in relation to the synthetic surfactants, as the biodegradability and low toxicity, and can be applied in the food industry, in pharmaceutical products, cosmetics and in the petroleum recovery. This paper aimed at selecting bacteria for biosurfactant production, evaluating the surface tension and the emulsifying activity and studying the fermentation process kinetics. The pure culture of Corynebacterium aquaticum showed capacity to promote emulsions formation and presented the smallest surface tension $\left(28.8 \mathrm{mN} \mathrm{m}^{-1}\right)$, and, in general, larger kinetic parameters, being selected as biosurfactant producer.
\end{abstract}

Keywords: bioprocess; emulsifying activity; surface tension.

\section{INTRODUÇÃO}

Os compostos de origem microbiana que exibem propriedades surfactantes, isto é, diminuem a tensão superficial e possuem alta capacidade emulsificante, são denominados biossurfactantes e consistem em produtos metabólicos de micro-organismos. ${ }^{1}$ São produzidos principalmente por bactérias isoladas do solo, da água do mar, de sedimentos marinhos e de áreas contaminadas por óleos. ${ }^{2}$

A maioria dos surfactantes em uso é derivada quimicamente do petróleo. Entretanto, o interesse por surfactantes microbiológicos tem aumentado nos últimos anos devido a sua diversidade, características ambientais favoráveis, possibilidade de produção através de fermentação e potencial aplicação em diversas áreas do setor industrial. ${ }^{3}$

Os biossurfactantes vêm sendo testados em aplicações ambientais como a biorremediação, dispersão de efluentes oleosos, otimização da recuperação de óleos e transferência de óleo cru. São compostos que podem substituir os surfactantes químicos no futuro, especialmente em indústrias de alimentos, cosmética e farmacêutica, produtos de limpeza industriais, produtos químicos agroindustriais e em processos de biorremediação, já que são biodegradáveis, possuem baixa toxicidade e apresentam estabilidade em valores extremos de $\mathrm{pH}$, temperatura e salinidade., ${ }^{4,5}$

A produção de bioemulsificantes ou compostos de superfície ativa geralmente ocorre no meio de cultura ou aderido às paredes celulares. As propriedades de superfície ativa mais importantes avaliadas na procura por micro-organismos produtores de biossurfactantes com potencial para aplicação industrial são a redução da tensão superficial, a formação de emulsão e capacidade de estabilização. ${ }^{6}$

Nesse contexto, o presente trabalho teve por objetivo selecionar bactérias com potencial para produção de biossurfactante, baseandose na redução da tensão superficial e aumento da atividade emulsificante, além da avaliação cinética dos processos fermentativos.

\section{PARTE EXPERIMENTAL}

Foram utilizadas 4 culturas de bactérias: 1) cultura pura de Corynebacterium aquaticum, 2) cultura mista contendo Corynebacterium aquaticum e Bacillus sp., 3) cultura mista contendo Corynebacterium sp., Bacillus cereus e Bacillus mycoides e 4) cultura pura de Bacillus

\footnotetext{
*e-mail: jorgealbertovc@ terra.com.br
}

subtilis. As culturas foram isoladas de efluentes provenientes da lavagem de caminhões transportadores de combustíveis, exceto a última.

As culturas de bactérias cresceram em meio de cultura contendo glicose (40,0 g L-1), $\mathrm{NH}_{4} \mathrm{NO}_{3}(50,0 \mathrm{mM}), \mathrm{Na}_{2} \mathrm{HPO}_{4}(3,0 \mathrm{mM}), \mathrm{KH}_{2} \mathrm{PO}_{4}$ (3,0 mM), $\mathrm{CaCl}_{2}(7,0 \mu \mathrm{M}), \mathrm{MgSO}_{4} \cdot 7 \mathrm{H}_{2} \mathrm{O}(0,8 \mathrm{mM})$, EDTA sódico $(4,0 \mu \mathrm{M})$, e $\mathrm{FeSO}_{4} .7 \mathrm{H}_{2} \mathrm{O}(2,0 \mathrm{mM}) \cdot{ }^{7,8}$

Os cultivos foram realizados em frascos Erlenmeyer de $1000 \mathrm{~mL}$ por $72 \mathrm{~h},{ }^{9}$ a $200 \mathrm{rpm},{ }^{7,10} 30{ }^{\circ} \mathrm{C},{ }^{11,12} \mathrm{e} \mathrm{o} \mathrm{pH}$ inicial foi fixado em $6,0 .{ }^{11}$

\section{Determinações analíticas}

A concentração celular foi determinada gravimetricamente após filtração do meio de cultura em membrana de acetato celulose. ${ }^{13} \mathrm{O}$ sobrenadante obtido foi utilizado para posteriores determinações analíticas, realizadas em triplicata, a cada $12 \mathrm{~h}$ do processo fermentativo. $\mathrm{O}$ pH foi determinado através de leitura direta em $\mathrm{pHmetro}$ digital (Quimis HI 8314, Brasil).

A estimativa da atividade biossurfactante foi obtida através da medida da tensão superficial e da determinação da atividade emulsificante. A tensão superficial foi determinada em tensiômetro (Kruss Processor Tensiometer K-6, Alemanha), no meio fermentado contendo, ou não, as células de micro-organismo. ${ }^{14,15}$ As atividades emulsificantes óleo em água e água em óleo foram determinadas utilizando-se 3,5 mL de amostra diluída e 2,0 mL de óleo de soja. A mistura foi agitada em agitador tipo vórtex (Phoenix AP56, Brasil) a $700 \mathrm{rpm}$ por $1 \mathrm{~min}$. Após $60 \mathrm{~min}$ de repouso foi lida a absorbância do meio emulsificado óleo/água em espectrofotômetro (Femto 700 Plus, Brasil) a $610 \mathrm{~nm},{ }^{16}$ calculando-se a atividade emulsificante óleo em água através da Equação 1. Após 24 h de repouso foi realizada leitura da altura da emulsão água/óleo formada e da altura total (altura da emulsão mais altura da camada remanescente de óleo), ${ }^{17}$ obtendo-se a atividade emulsificante água em óleo de acordo com a Equação 2.

$$
\begin{aligned}
& A E_{o / a}=\left(A b s_{\text {amostra }}-A b s_{\text {branco }}\right) \cdot D \\
& A E_{\text {a/o }}=\left(E_{\text {amostra }}-E_{\text {branco }}\right) \cdot D
\end{aligned}
$$

onde: $\mathrm{AE}_{\mathrm{o} / \mathrm{a}}=$ atividade emulsificante óleo em água (UE); $\mathrm{AE}_{\mathrm{a} / \mathrm{o}}=$ atividade emulsificante água em óleo (UE); $\mathrm{Abs}_{\text {amostra }}=$ absorbância da emulsão óleo/água; $\mathrm{Abs}_{\text {branco }}=$ absorbância da amostra diluída; $\mathrm{E}_{\text {amostra }}=$ relação centesimal entre a altura da emulsão água/óleo e a altura total utilizando amostra; $\mathrm{E}_{\text {branco }}=$ relação centesimal entre 
a altura da emulsão água/óleo e a altura total utilizando água; $\mathrm{D}$ = diluição da amostra em água.

A atividade emulsificante óleo em água foi definida como a quantidade de biossurfactante necessária para aumentar a absorbância em 1,0 a $610 \mathrm{~nm}$, e a atividade emulsificante água em óleo como a quantidade de biossurfactante necessária para manter a emulsão estável por 24 h. ${ }^{18}$

\section{Avaliação de parâmetros cinéticos}

Os parâmetros cinéticos velocidade instantânea máxima de crescimento celular e de formação de produto, tempo de geração e a produtividade máxima em produto durante os cultivos foram determinados através das Equações 3, 4, 5 e $6 .{ }^{19}$ A velocidade específica máxima de crescimento celular foi obtida por regressão exponencial da fase logarítmica da curva de crescimento.

$$
\begin{aligned}
& r_{X}=\frac{d X}{d t} \\
& t g=\frac{\ln 2}{\mu_{\text {máx }}} \\
& r_{P}=\frac{d P}{d t} \\
& P_{P}=\frac{P-P_{0}}{t}
\end{aligned}
$$

onde: $r_{x}=$ velocidade instantânea de crescimento celular $\left(\mathrm{g}_{\text {cél }} \mathrm{L}^{-1}\right.$ $\left.\mathrm{h}^{-1}\right) ; \mathrm{X}=$ concentração celular $\left(\mathrm{g}_{\text {cél }} \mathrm{L}^{-1}\right) ; \operatorname{tg}=$ tempo de geração $(\mathrm{h})$; $\mu_{\text {máx }}=$ velocidade específica máxima de crescimento celular $\left(\mathrm{h}^{-1}\right) ; \mathrm{r}_{\mathrm{p}}$ $=$ velocidade instantânea de formação de produto $\left(\mathrm{g}_{\text {prod }} \mathrm{L}^{-1} \mathrm{~h}^{-1}\right) ; \mathrm{P}_{\mathrm{p}}=$ produtividade em produto $\left(\mathrm{g}_{\text {prod }} \mathrm{L}^{-1} \mathrm{~h}^{-1}\right) ; \mathrm{P}=$ concentração de produto no tempo $\mathrm{t}\left(\mathrm{g}_{\text {prod }} \mathrm{L}^{-1}\right) ; \mathrm{P}_{0}=$ concentração de produto no início da fermentação $\left(\mathrm{g}_{\text {prod }} \mathrm{L}^{-1}\right) ; \mathrm{t}=$ tempo de cultivo $(\mathrm{h})$.

Como a produção de biossurfactante foi verificada através de métodos indiretos, a concentração de produto foi expressa em unidade de tensão superficial $\left(\mathrm{mN} \mathrm{m}^{-1}\right)$ ou de atividade emulsificante (UE).

\section{Análise estatística}

Os experimentos com as diferentes culturas de bactérias foram realizados em duplicata. Os resultados obtidos foram tratados por análise de variância (ANOVA) das duplicatas dos experimentos, a um nível de significância de 5\%, através do teste de comparação de médias de Tukey, com o auxílio do software Statistica 6.0. Foram analisadas diferenças entre os valores das tensões superficiais do meio fermentado na presença e na ausência das células de micro-organismo, nos diferentes tempos de amostragem dos cultivos, a fim de verificar se a produção de biossurfactante foi extracelular e aderida à parede celular, ou somente extracelular. A bactéria com potencial para produzir biossurfactante foi selecionada comparando-se os menores valores das tensões superficiais e os maiores valores das atividades emulsificantes encontrados em cada experimento, bem como pela avaliação dos parâmetros cinéticos.

\section{RESULTADOS E DISCUSSÃO}

Os resultados médios encontrados para as tensões superficiais do meio fermentado na presença ou ausência das células de microorganismos e para o crescimento celular nos diferentes experimentos são mostrados na Figura 1.
Os biossurfactantes podem ser liberados extracelularmente no meio de cultura ou aderidos à célula do micro-organismo. ${ }^{20}$ A única cultura que apresentou diferença significativa $(\mathrm{p}<0,05)$ entre os valores de tensão superficial no meio com e sem células de bactéria, em um mesmo tempo de cultivo, foi a cultura pura de Corynebacterium aquaticum, nos tempos 24 e 36 h. Este fato indica provável produção de biossurfactante aderido à parede celular por essa bactéria, além de extracelular. Para as demais culturas, em um mesmo tempo de cultivo, não houve diferença significativa $(p>0,05)$ entre as tensões superficiais, o que indica produção extracelular de biossurfactante.

(a)

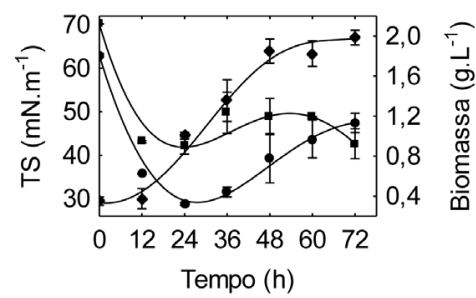

(b)

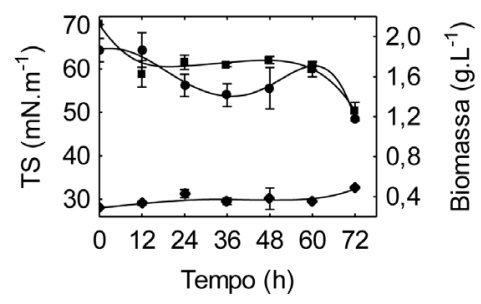

(c)

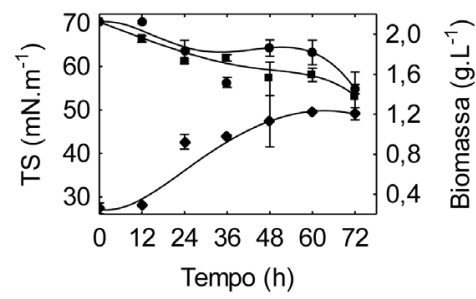

(d)

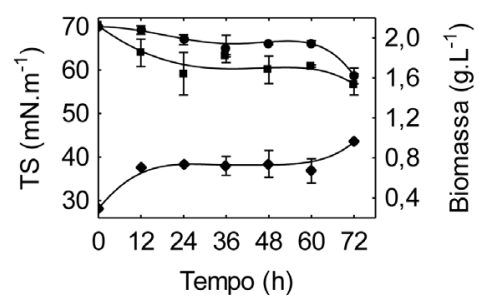

Figura 1. Biomassa de bactérias e tensões superficiais (TS) antes e após filtração do meio fermentado. (a) Cultura pura de Corynebacterium aquaticum, (b) cultura mista de Corynebacterium aquaticum e Bacillus sp., (c) cultura mista de Corynebacterium sp., Bacillus cereus e Bacillus mycoides $e$ (d) cultura pura de Bacillus subtilis. Biomassa, • tensão superficial do meio de cultura na presença das células de micro-organismos e $\mathbf{\square}$ tensão superficial do meio de cultura na ausência das células de micro-organismos

Bactérias foram isoladas de locais contaminados com petróleo e foi verificado que 8 dos 17 isolados foram capazes de reduzir a tensão superficial para valores abaixo de $40 \mathrm{mN} \mathrm{m}^{-1}$; desses 8 , somente 5 foram capazes de reduzir a tensão superficial do sobrenadante livre de células, o que indicou que os outros 3 produziram biossurfactante somente aderido ou como parte da parede celular. Para um dos iso- 
lados, a tensão superficial do meio na presença de células foi 33,4 $\pm 2,0 \mathrm{mN} \mathrm{m}^{-1}$ e a tensão do sobrenadante livre de células foi 42,3 \pm $9,93 \mathrm{mN} \mathrm{m}^{-1},{ }^{6}$ valores próximos ao encontrado no presente trabalho para a bactéria Corynebacterium aquaticum.

A maior concentração celular foi obtida no cultivo da bactéria Corynebacterium aquaticum $\left(1,98 \mathrm{~g} \mathrm{~L}^{-1}\right)$, seguida pelos cultivos da cultura mista de Corynebacterium sp., Bacillus cereus e Bacillus mycoides $\left(1,23 \mathrm{~g} \mathrm{~L}^{-1}\right)$, cultura pura de Bacillus subtilis $\left(0,96 \mathrm{~g} \mathrm{~L}^{-1}\right) \mathrm{e}$ cultura mista de Corynebacterium aquaticum e Bacillus sp. (0,48 g $\left.\mathrm{L}^{-1}\right)$. O pH diminuiu ao longo das fermentações, indicando a produção de metabólitos ácidos pelas culturas de bactérias utilizadas (dados não mostrados).

Além de reduzir tensões superficiais e interfaciais, os biossurfactantes usualmente exibem capacidade emulsificante. ${ }^{21}$ A Figura 2 mostra o comportamento médio das atividades emulsificantes óleo em água e água em óleo ao longo do tempo de fermentação para cada cultura. Maiores atividades emulsificantes, tanto óleo em água quanto água em óleo, foram obtidas em 60 ou 72 h de cultivo.

(a)

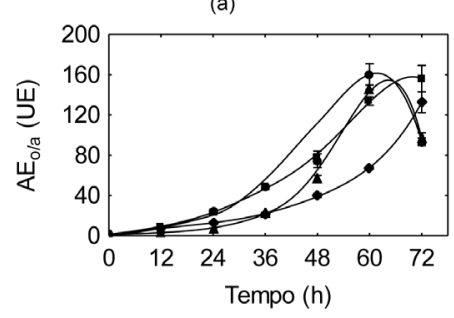

(b)

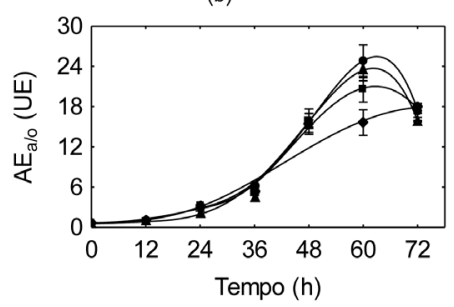

Figura 2. Atividades emulsificantes óleo em água e água em óleo durante os cultivos com diferentes culturas de bactérias. (a) Atividade emulsificante óleo em água $\left(A E_{o / a}\right)$ e $(b)$ atividade emulsificante água em óleo $\left(A E_{a / o}\right)$. Cultura pura de Corynebacterium aquaticum, - cultura mista de Corynebacterium aquaticum e Bacillus sp., $\diamond$ cultura mista de Corynebacterium sp., Bacillus cereus e Bacillus mycoides e $\mathbf{\Delta}$ cultura pura de Bacillus subtilis

Um dos critérios adotados para selecionar uma entre as quatro culturas utilizadas foi a comparação dos menores valores das tensões superficiais e dos maiores valores de atividades emulsificantes obtidos para as diferentes culturas, o que pode ser observado na Tabela 1. A menor tensão superficial foi encontrada para a bactéria Corynebacterium aquaticum $\left(28,8 \mathrm{mN} \mathrm{m}^{-1}\right)$, no meio de cultura contendo células de micro-organismo, diferindo significativamente $(\mathrm{p}<0,05)$ das tensões encontradas para as demais culturas. Com relação às menores tensões do meio de cultura filtrado, a cultura de Corynebacterium aquaticum diferiu significativamente somente da cultura de Bacillus subtillis $(\mathrm{p}<0,05)$. As maiores atividades emulsificantes óleo em água e água em óleo não diferiram para todas as culturas $(\mathrm{p}>0,05)$.

Os critérios utilizados para selecionar micro-organismos produtores de biossurfactante são a habilidade em reduzir a tensão superficial abaixo de $40 \mathrm{mN} \mathrm{m}^{-1}$ e a capacidade de estabilização da emulsão, a habilidade em manter pelo menos $50 \%$ do volume da emulsão original $24 \mathrm{~h}$ depois da sua formação. ${ }^{6}$ As culturas de bactérias utilizadas neste trabalho foram capazes de produzir biossurfactante,
Tabela 1. Valores mínimos das tensões superficiais e valores máximos das atividades emulsificantes durante os cultivos das culturas pura de Corynebacterium aquaticum (Cultura 1), mista de Corynebacterium aquaticum e Bacillus sp. (Cultura 2), mista de Corynebacterium sp., Bacillus cereus e Bacillus mycoides (Cultura 3) e pura de Bacillus subtilis (Cultura 4)

\begin{tabular}{lcccc}
\hline Cultura & $\begin{array}{c}\mathrm{TS}_{\text {pre cél }} \\
\left(\mathrm{mN} \mathrm{m}^{-1}\right)\end{array}$ & $\begin{array}{c}\mathrm{TS}_{\text {aus cél }} \\
\left(\mathrm{mN} \mathrm{m}^{-1}\right)\end{array}$ & $\mathrm{AE}_{\mathrm{o} / \mathrm{a}}(\mathrm{UE})$ & $\mathrm{AE}_{\mathrm{a} / \mathrm{o}}(\mathrm{UE})$ \\
\hline 1 & $28,8 \pm 0,3^{\mathrm{a}}$ & $42,3 \pm 2,1^{\mathrm{a}}$ & $160,34 \pm 11,13^{\mathrm{a}}$ & $24,84 \pm 2,47^{\mathrm{a}}$ \\
2 & $48,4 \pm 0,4^{\mathrm{b}}$ & $50,3 \pm 2,1^{\mathrm{ab}}$ & $156,19 \pm 13,72^{\mathrm{a}}$ & $20,50 \pm 1,90^{\mathrm{a}}$ \\
3 & $54,8 \pm 1,1^{\mathrm{c}}$ & $53,2 \pm 5,8^{\mathrm{ab}}$ & $132,71 \pm 10,90^{\mathrm{a}}$ & $17,91 \pm 0,54^{\mathrm{a}}$ \\
4 & $58,7 \pm 1,9^{\mathrm{c}}$ & $56,7 \pm 2,6^{\mathrm{b}}$ & $145,21 \pm 0,15^{\mathrm{a}}$ & $23,47 \pm 1,69^{\mathrm{a}}$ \\
\hline
\end{tabular}

$\mathrm{TS}_{\text {pre cél }}=$ tensão superficial do meio fermentado na presença das células de micro-organismos; $\mathrm{TS}_{\text {aus cél }}=$ tensão superficial do meio fermentado na ausência das células de micro-organismos; $\mathrm{AE}_{\mathrm{o} / \mathrm{a}}=$ atividade emulsificante óleo em água; $\mathrm{AE}_{\mathrm{a} / \mathrm{o}}=$ atividade emulsificante água em óleo. Letras iguais correspondem aos valores que não apresentaram diferença significativa (nível de significância de $5 \%)$ para cada resposta estudada.

reduzindo a tensão superficial do meio e levando ao aumento da atividade emulsificante. Porém, a cultura pura de Corynebacterium aquaticum destacou-se dentre as estudadas pela tensão superficial do meio fermentado na presença de células da bactéria.

Os gêneros de bactérias utilizados no presente trabalho (Corynebacterium e Bacillus) têm sido reportados na literatura como produtores de biossurfactante. $\mathrm{O}$ aumento da produção de biossurfactante por Corynebacterium alkanolyticum ATCC 21511 foi verificado utilizando hexadecano como substrato. O biossurfactante do tipo fosfolipídio produzido foi capaz de reduzir a tensão superficial para valores abaixo de $32 \mathrm{mN} \mathrm{m}^{-1}$. $^{22}$

Um estudo analisou a produção de biossurfactante por duas espécies de bactérias do gênero Bacillus. A bactéria Bacillus cereus foi capaz de reduzir a tensão superficial do meio para $28 \mathrm{mN} \mathrm{m}^{-1} \mathrm{e}$ apresentar índice emulsificante em torno de $60 \%$, tanto no meio na presença quanto na ausência das células do micro-organismo, o que indicou produção extracelular de biossurfactante. Já a bactéria Bacillus $s p$. IAF 343 não ocasionou apreciável redução da tensão superficial, porém o índice emulsificante ficou em torno de $60 \%$, tanto no meio na presença quanto na ausência das células da bactéria. ${ }^{23}$

No cultivo da bactéria Corynebacterium aquaticum verificou-se que a tensão superficial diminuiu rapidamente até $12 \mathrm{~h}$ de cultivo, enquanto o crescimento celular foi baixo. Comportamento semelhante foi encontrado na avaliação da produção de biossurfactante por culturas de Lactobacillus. A redução da tensão superficial ocorreu principalmente nas primeiras $4 \mathrm{~h}$ de cultivo, quando o crescimento do micro-organismo era quase inexistente e o consumo de substrato era baixo. ${ }^{15}$

As culturas pura de Corynebacterium aquaticum, mista de Corynebacterium aquaticum e Bacillus sp. e mista de Corynebacterium sp., Bacillus cereus e Bacillus mycoides foram isoladas da água de lavagem de caminhões transportadores de combustíveis, porém a cultura pura de Bacillus subtilis não o foi. Os micro-organismos produtores de biossurfactantes geralmente são isolados de locais contaminados com hidrocarbonetos, em que as condições selecionam micro-organismos com habilidade de utilizar fontes hidrofóbicas de carbono. Entretanto, existem relatos de produtores isolados de locais não contaminados, o que pode ocorrer devido a outros papéis dos biossurfactantes, como biocidas, fungicidas e transportadores de moléculas de nutrientes. ${ }^{24}$ 
A produção de biossurfactante pode ser induzida por hidrocarbonetos ou substratos insolúveis em água. Porém, os biossurfactantes também podem ser produzidos a partir de substratos solúveis em água, especialmente carboidratos..$^{20,21,25}$

Hidrocarbonetos e carboidratos estão envolvidos na síntese das porções hidrofóbicas e hidrofílicas, respectivamente, das moléculas de biossurfactante. As seguintes possibilidades existem para a síntese das diferentes porções das moléculas de biossurfactantes e seu acoplamento: as porções hidrofóbica e hidrofílica são sintetizadas de forma independente; a porção hidrofílica é sintetizada enquanto a síntese da porção hidrofóbica é induzida pelo substrato; a porção hidrofóbica é sintetizada, enquanto a síntese da porção hidrofílica é dependente do substrato e, a síntese de ambas porções hidrofóbica e hidrofílica é dependente do substrato. ${ }^{20}$

Como as culturas pura de Corynebacterium aquaticum, mista de Corynebacterium aquaticum e Bacillus sp. e mista de Corynebacterium sp., Bacillus cereus e Bacillus mycoides utilizadas no presente trabalho foram isoladas de ambientes contendo hidrocarbonetos e cultivadas em meio contendo carboidrato (glicose) como fonte de carbono, a síntese das porções hidrofóbica e hidrofílica das moléculas de biossurfactante pode ter ocorrido de diferentes maneiras: de forma independente; quando na presença de hidrocarbonetos, a síntese da porção hidrofóbica pode ter sido induzida pelo substrato; e quando na presença de glicose, a síntese da porção hidrofílica pode ter sido substrato dependente.

A bactéria Bacillus subtilis é uma das mais citadas na literatura por produzir o biossurfactante conhecido como surfactina e reduzir consideravelmente a tensão superficial. Provavelmente, a cultura utilizada neste trabalho, isolada de local não contaminado com óleos, não apresentou redução da tensão superficial comparável à encontrada na literatura por não conseguir sintetizar de forma independente as porções hidrofóbicas e hidrofílicas das moléculas de biossurfactante ou, ainda, pela síntese da porção hidrofóbica ser dependente do substrato, sendo necessária a presença de fonte de carbono hidrofóbica no meio.

A maioria dos biossurfactantes são liberados no meio de cultura na fase exponencial ou na fase estacionária do crescimento microbiano. ${ }^{26}$ Quando se utilizaram as culturas pura de Corynebacterium aquaticum e mista de Corynebacterium sp., Bacillus cereus e Bacillus mycoides, biossurfactantes foram liberados no meio de cultura na fase exponencial e estacionária de crescimento. Já para as culturas mista de Corynebacterium aquaticum e Bacillus sp. e pura de Bacillus subtillis, a maioria dos biossurfactantes foram liberados na fase estacionária (Figuras 1 e 2).

A Tabela 2 apresenta os parâmetros cinéticos avaliados durante a produção de biossurfactante por diferentes culturas de bactérias. Com exceção das velocidades instantâneas máximas de formação de produto para as atividades emulsificantes, da velocidade específica máxima de crescimento celular e do tempo de geração, os maiores parâmetros cinéticos foram encontrados para a cultura de Corynebacterium aquaticum.

$\mathrm{Na}$ fase exponencial, a velocidade específica de crescimento é máxima e constante. ${ }^{19}$ A maior velocidade específica de crescimento celular $\left(0,063 \mathrm{~h}^{-1}\right)$ foi encontrada no cultivo da bactéria Bacillus subtilis. A cultura mista de Corynebacterium aquaticum e Bacillus sp. foi a que apresentou menor velocidade específica de crescimento celular $(0,010$ $\left.\mathrm{h}^{-1}\right)$. Além disso, essa cultura foi a que propiciou menor concentração celular $\left(0,48 \mathrm{~g} \mathrm{~L}^{-1}\right)$ e maior tempo de geração $(69,3 \mathrm{~h})$.

A concentração celular máxima foi atingida pela cultura de Corynebacterium aquaticum $\left(1,98 \mathrm{~g} \mathrm{~L}^{-1}\right)$. Fontes de carbono solúveis (carboidratos) e insolúveis (hidrocarbonetos) em água foram estudadas na produção de biossurfactante por Bacillus subtilis. Quando a glicose foi utilizada como fonte de carbono, a biomassa atingida foi $1,85 \mathrm{~g}$ $\mathrm{L}^{-1},{ }^{27}$ valor próximo ao encontrado no presente trabalho para a bactéria Corynebacterium aquaticum.

As maiores velocidades instantâneas de crescimento celular foram, em ordem descrescente: $0,042 \mathrm{~g} \mathrm{~L}^{-1} \mathrm{~h}^{-1}$ (Corynebacterium aquaticum);
Tabela 2. Parâmetros cinéticos determinados para as culturas pura de Corynebacterium aquaticum (Cultura 1), mista de Corynebacterium aquaticum e Bacillus sp. (Cultura 2), mista de Corynebacterium sp., Bacillus cereus e Bacillus mycoides (Cultura 3) e pura de Bacillus subtilis (Cultura 4)

\begin{tabular}{lcccc}
\hline \multirow{2}{*}{ Parâmetro cinético } & \multicolumn{4}{c}{ Cultura } \\
\cline { 2 - 5 } & 1 & 2 & 3 & 4 \\
\hline $\mathrm{X}_{\text {máx }}\left(\mathrm{g}_{\text {cél }} \mathrm{L}^{-1}\right)$ & 0,042 & 0,003 & 0,026 & 0,007 \\
$\mathrm{r}_{\mathrm{X}}\left(\mathrm{g}_{\text {cél }} \mathrm{L}^{-1} \mathrm{~h}^{-1}\right)$ & 0,043 & 0,010 & 0,037 & 0,063 \\
$\mu_{\text {máx }}\left(\mathrm{h}^{-1}\right)$ & 16,1 & 69,3 & 18,7 & 11,0 \\
$\operatorname{tg}(\mathrm{h})$ & 1,36 & 0,45 & 0,35 & 0,21 \\
$\mathrm{r}_{\mathrm{P}}-\mathrm{TS}_{\text {pre cél }}\left(\mathrm{mN} \mathrm{m}^{-1} \mathrm{~h}^{-1}\right)$ & 1,10 & 0,39 & 0,30 & 0,37 \\
$\mathrm{r}_{\mathrm{P}}-\mathrm{TS}_{\text {aus cél }}\left(\mathrm{mN} \mathrm{m}^{-1} \mathrm{~h}^{-1}\right)$ & 4,45 & 4,15 & 3,40 & 5,93 \\
$\mathrm{r}_{\mathrm{P}}-\mathrm{AE}_{\mathrm{o} / \mathrm{a}}\left(\mathrm{UE} \mathrm{h}^{-1}\right)$ & 0,80 & 0,71 & 0,39 & 0,83 \\
$\mathrm{r}_{\mathrm{P}}-\mathrm{AE}_{\mathrm{a} / \mathrm{o}}\left(\mathrm{UE} \mathrm{h}^{-1}\right)$ & 2,01 & 0,31 & 0,24 & 0,12 \\
$\mathrm{P}_{\mathrm{P}}-\mathrm{TS}_{\text {pre cél }}\left(\mathrm{mN} \mathrm{m}^{-1} \mathrm{~h}^{-1}\right)$ & 1,89 & 0,73 & 0,30 & 0,49 \\
$\mathrm{P}_{\mathrm{P}}-\mathrm{TS}_{\text {aus cél }}\left(\mathrm{mN} \mathrm{m}^{-1} \mathrm{~h}^{-1}\right)$ & 2,65 & 2,19 & 1,11 & 2,40 \\
$\mathrm{P}_{\mathrm{P}}-\mathrm{AE}_{\mathrm{o} / \mathrm{a}}\left(\mathrm{UE} \mathrm{h}^{-1}\right)$ & 0,40 & 0,33 & 0,25 & 0,38 \\
$\mathrm{P}_{\mathrm{P}}-\mathrm{AE}_{\mathrm{a} / \mathrm{o}}\left(\mathrm{UE} \mathrm{h}^{-1}\right)$ &
\end{tabular}

$\mathrm{X}_{\text {máx }}=$ concentração celular máxima; $r_{x}=$ velocidade instantânea máxima de crescimento celular; $\mu_{\operatorname{máx}}=$ velocidade específica máxima de crescimento celular; $\operatorname{tg}=$ tempo de geração; $r_{p}=$ velocidade instantânea máxima de formação de produto; $\mathrm{P}_{\mathrm{P}}=$ produtividade máxima em produto; $\mathrm{TS}_{\text {pre cél }}=$ tensão superficial do meio fermentado na presença das células de micro-organismo; $\mathrm{TS}_{\text {aus cél }}=$ tensão superficial do meio fermentado na ausência das células de micro-organismo; $\mathrm{AE}_{\mathrm{o} / \mathrm{a}}=$ atividade emulsificante óleo em água; $\mathrm{AE}_{\mathrm{a} / \mathrm{o}}=$ atividade emulsificante água em óleo.

$0,026 \mathrm{~g} \mathrm{~L}^{-1} \mathrm{~h}^{-1}$ (Corynebacterium sp., Bacillus cereus e Bacillus mycoides); $0,007 \mathrm{~g} \mathrm{~L}^{-1} \mathrm{~h}^{-1}$ (Bacillus subtilis) e $0,003 \mathrm{~g} \mathrm{~L}^{-1} \mathrm{~h}^{-1}$ (Corynebacterium aquaticum e Bacillus sp.). A mesma ordem decrescente, com relação às culturas, foi encontrada para a concentração celular máxima.

As maiores produtividades com relação à redução das tensões superficiais do meio fermentado na presença ou ausência das células de bactéria foram $2,01 \mathrm{mN} \mathrm{m}^{-1} \mathrm{~h}^{-1} \mathrm{e} 1,89 \mathrm{mN} \mathrm{m}^{-1} \mathrm{~h}^{-1}$, respectivamente, obtidas para a bactéria Corynebacterium aquaticum. Já com relação às atividades emulsificantes óleo em água e água em óleo, as produtividades nos cultivos de Corynebacterium aquaticum (2,65 e 0,40 $\mathrm{UE} \mathrm{h}^{-1}$, respectivamente) e de Bacillus subtilis $\left(2,40\right.$ e $0,38 \mathrm{UE} \mathrm{h}^{-1}$, respectivamente) foram próximas. Além disso, as maiores velocidades instantâneas de formação de produto relacionadas às atividades emulsificantes óleo em água $\left(5,93 \mathrm{UE} \mathrm{h}^{-1}\right)$ e água em óleo (0,83 UE $\mathrm{h}^{-1}$ ) também foram obtidas a partir da cultura de Bacillus subtilis, o que sugere que, apesar desta bactéria não ter sido eficiente na redução da tensão superficial, foi capaz de promover a formação de emulsões comparáveis as obtidas no cultivo de Corynebacterium aquaticum.

\section{CONCLUSÃO}

A cultura pura de Corynebacterium aquaticum foi a que apresentou menor tensão superficial $\left(28,8 \mathrm{mN} \mathrm{m}^{-1}\right)$, no meio de cultura na presença de células de micro-organismos, diferindo $(\mathrm{p}<0,05)$ das demais culturas utilizadas. As maiores produtividades relacionadas à redução da tensão superficial $\left(2,01 \mathrm{mN} \mathrm{m}^{-1} \mathrm{~h}^{-1}\right)$, à atividade emulsificante óleo em água $\left(2,65 \mathrm{UE} \mathrm{h}^{-1}\right)$ e à atividade emulsificante água em óleo $\left(0,40 \mathrm{UE} \mathrm{h}^{-1}\right)$ foram obtidas no cultivo de Corynebacterium aquaticum. 
Os resultados mostraram a potencialidade da bactéria Corynebacterium aquaticum na produção de biossurfactante, tanto pela redução da tensão superficial e aumento da atividade emulsificante quanto pelos parâmetros cinéticos avaliados, podendo o biossurfactante produzido por essa bactéria ser utilizado tanto na emulsão de alimentos, após purificação e testes de toxicidade, como em processos de biorremedição.

\section{REFERÊNCIAS}

1. Makkar, R. S.; Cameotra, S. S.; J. Ind. Microbiol. Biotechnol. 1998, $20,48$.

2. Barros, F. F. C.; Quadros, C. P.; Maróstica Jr., M. R.; Pastore, G. M.; Quim. Nova 2007, 30, 409.

3. Kim, S. H.; Lim, E. J.; Lee, S. O.; Lee, J. D.; Lee, T. H.; Biotechnol. Appl. Biochem. 2000, 31, 249.

4. Chen, S. Y.; Lu, W. B.; Wei, Y. H.; Chen, W. M.; Chang, J. S.; Biotechnol. Prog. 2007, 23, 661.

5. Makkar, R. S.; Cameotra, S. S.; Appl. Microbiol. Biotechnol. 2002, 58, 428.

6. Batista, S. B.; Mounteer, A. H.; Amorim, F. R.; Tótola, M. R.; Bior. Technol. 2006, 97, 868 .

7. Yeh, M. S.; Wei, Y. H.; Chang, J. S.; Biotechnol. Prog. 2005, 21, 1329.

8. Wei, Y. H.; Wang, L. F.; Chang, J. S.; Biotechnol. Prog. 2004, 20, 979.

9. Fox, S. L.; Bala, G. A.; Bioresour. Technol. 2000, 75, 235.

10. Wei, Y. H.; Wang, L. F.; Chang, J. S.; Kung, S. S.; J. Biosci. Bioeng. 2003, 96, 174.

11. Nitschke, M.; Pastore, G. M.; Bioresour. Technol. 2006, 97, 336.
12. Rocha, M. V. P.; Oliveira, A. H. S.; Souza, M. C. M.; Gonçalves, L. R. B.; World J. Microbiol. Biotechnol. 2006, 22, 1295.

13. Thavasi, R.; Jayalakshmi, S.; Balasubramanian, T.; Banat, I. M.; Lett. Appl. Microbiol. 2007, 45, 686.

14. Costa, S. G. V. A. O.; Nitschke, M.; Haddad, R.; Eberlin, M. N.; Contiero, J.; Process Biochem. 2006, 41, 483.

15. Rodrigues, L.; Moldes, A.; Teixeira, J.; Oliveira, R.; Biochem. Eng. J. 2006, $28,109$.

16. Johnson, V.; Singh, M.; Saini, V. S.; Adhikari, D. K.; Sista, V.; Yadav, N. K.; Biotechnol. Lett. 1992, 14, 487.

17. Broderick, L. S.; Cooney, J. J.; Dev. Ind. Microbiol. 1982, 23, 425.

18. Martins, V. G.; Dissertação de Mestrado, Universidade Federal do Rio Grande, Brasil, 2005.

19. Schmidell, W.; Lima, U. A.; Aquarone, E.; Borzani, W.; Biotecnologia Industrial, Edgard Blücher LTDA: São Paulo, 2001, vol. 2.

20. Desai, J. D.; Banat, I. M.; Microbiol. Mol. Biol. Rev. 1997, 61, 47.

21. Karanth, N. G. K.; Deo, P. G.; Veenanadig, N. K.; Curr. Sci. 1999, 77, 116.

22. Crosman, J. T.; Pinchuk, R. J.; Cooper, D. G.; J. Am. Oil Chem. Soc. 2002, 79, 467.

23. Cooper, D. G.; Goldenberg, B. G.; Appl. Environ. Microbiol. 1987, 53, 224.

24. Jennings, E. M.; Tanner, R. S.; Proceedings of the 2000 Conference on Hazardous Waste Research, Manhattan, USA, 2000.

25. Mulligan, C.; Environ. Pollut. 2005, 133, 183.

26. Cameotra, S. S.; Makkar, R. S.; Appl. Microbiol. Biotechnol. 1998, 50, 520.

27. Makkar, R. S.; Cameotra, S. S.; J. Ind. Microbiol. Biotechnol. 1997, 18, 37. 